\title{
A confirmatory factor analytical study of a servant leadership measure in South Africa
}

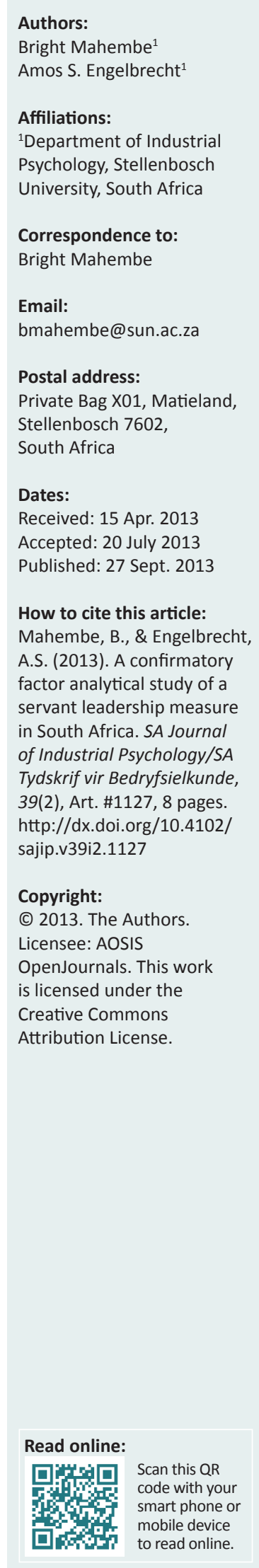

Orientation: Servant leadership is a value-based leadership practice that plays a critical role in team effectiveness and organisational success.

Research purpose: The goal of the study was to validate the Servant Leadership Questionnaire (SLQ), which Barbuto and Wheeler developed, on a South African sample.

Motivation for the study: The literature is replete with evidence of the role of followerfocused leadership practices in improving team effectiveness, employee engagement and organisational success. We need to complement these efforts with psychometrically sound measuring instruments.

Research design, approach and method: The authors drew a convenience sample of 288 school teachers from schools in the Western Cape Province of South Africa. They used the SLQ that Barbuto and Wheeler developed to measure servant leadership.

Main findings: The authors found high levels of reliability for the sub-scales of the latent variables. They found good fit with the data for the measurement model of the five latent servant leadership dimensions (altruistic calling, persuasive mapping, emotional healing, wisdom and organisational stewardship) through confirmatory factor analyses (CFA). They obtained reasonable fit for the first- and second-order servant leadership CFA. The authors concluded that the SLQ shows reasonable fit.

Practical/managerial implications: The SLQ showed evidence of reliability and construct validity. It can contribute to the scientific selection and development of education leaders in South African schools.

Contribution/value add: Servant leadership incorporates a service ethic that fosters participatory management, teacher development and team building. The department of education should increase team effectiveness in schools by selecting and developing servant leadership.

\section{Introduction}

In the relatively new field of positive psychology, researchers have recently identified leadership as essential for fostering employee engagement, team effectiveness and organisational success (Avolio \& Gardner, 2005; Macik-Frey, Quick \& Cooper, 2009). One of the contemporary leadership styles that have become relevant in positive psychology is servant leadership (Sendjaya \& Cooper, 2011; Van Dierendonck, 2011).

Servant leadership (SL) comprises an understanding and practice of leadership that places the good of those who follow above the self-interest of leaders (Laub, 2004). Servant leaders have true commitment to their followers and serve the needs of followers mainly. Therefore, they provide vision, empowerment and service as their main activities. Servant leadership is virtuous (Patterson, 2003), highly ethical (Whetstone, 2002; Wong \& Page, 2003) and uses the premise that service to followers is at the heart of leadership (Sendjaya Sarros \& Santora, 2008; Spears, 2010).

Despite the relevance of servant leadership in the work context, the absence of a universal definition and measure affects the concept (Van Dierendonck, 2011). The research of Barbuto and Wheeler (2006) on servant leadership culminated in refining the definitions of Greenleaf and Spears: It is a five-dimensional construct that comprises altruistic calling, emotional healing, persuasive mapping, wisdom and organisational stewardship. An earlier attempt to replicate their findings with a South African sample failed, suggesting that this instrument might actually be only one-dimensional (Dannhauser \& Boshoff, 2007). However, Sun and Wang (2009) argued that the construct validity of the five dimensions of the Servant Leadership Questionnaire (SLQ) might still hold in different cultural contexts. 
Instead of focusing on the South African motor industry (Dannhauser \& Boshoff, 2007), the current study tested the underlying SLQ model in the education sector. Taylor, Martin, Hutchinson and Jinks (2007) assert that principals who embrace their role as servant leaders focus on creating school settings in which teachers work towards a shared vision and are committed to their schools.

\section{Aim of the study}

The main objective of the study was to determine the construct validity of the Servant Leadership Questionnaire, which Barbuto and Wheeler (2006) developed, for the South African context. More specifically, the sub-objectives of the study were to investigate:

- The reliability of the SLQ by computing the Cronbach alpha reliability coefficients for each of the subscales.

- The construct validity of the SLQ by means of first- and second-order confirmatory factor analyses (CFA).

\section{A review of the literature}

In recent years, servant leadership has gained considerable popularity, as the increasing number of scholarly articles on the subject shows (Han, Kakabadse \& Kakabadse, 2010; Lidean, Wayne, Zhao \& Henderson, 2008; Schneider \& George, 2011; Sendjaya \& Cooper, 2011; Van Dierendonck \& Nuijten, 2011).

Much of the earlier work on servant leadership focused on identifying themes to operationalise the concept. Table 1 summarises it.

\section{Comparing servant leadership and other value- based leadership styles}

\section{Servant leadership and transformational leadership}

The servant and transformational leadership styles are similar in that they are both value based. However, the two leadership styles differ in terms of the focus of the leaders. Transformational leadership focuses on developing followers through idealised influence, individualised consideration, intellectual stimulation and inspirational motivation (Bass, 1985; Burns, 1978).
According to Bass (1985), leaders transform and motivate followers by:

1. Making them aware of the importance of the outcomes of tasks.

2. Inducing them to transcend their own self-interest for the sake of their organisations.

3. Activating their higher-order needs.

For transformational leaders, achieving the objectives of their organisations is their most important activity. On the other hand, servant leaders focus on the followers' needs (Parolini, Patterson \& Winston, 2009). Yukl (2013) commented that the servant leadership emphasis on the welfare of followers could be problematic when the needs of organisations are incompatible with the welfare of employees. An example of such a challenge is when the leaders in a company need to consider drastic measures like downsizing, outsourcing or reducing benefits in order to remain profitable. Despite the differences in the areas of focus, transformational leadership incorporates the idealised influence attribute that is absent in servant leadership, whilst servant leadership focuses on humility, authenticity and interpersonal acceptance, none of which is an explicit element of transformational leadership (Parolini, Patterson \& Winston, 2009).

\section{Servant leadership and authentic leadership}

Increased self-awareness, relational transparency, internalised transparency, an internalised moral perspective and balanced processing to encourage authenticity in followers motivate authentic leaders. This involves focusing on owning one's personal experiences, like thoughts, emotions, needs, wants, preferences or beliefs. One takes responsibility for one's life and for the choices one makes (Avolio \& Gardener, 2005). According to Ladkin and Taylor (2010), the core aspect of authentic leadership is the manifestation of leadership as an expression of the 'true self'. Walumbwa, Avolio, Gardner, Wernsing and Peterson (2008) operationalised this 'true self' concept as one that focuses on being authentic in one's interactions with others and being true to one's inner thoughts, whilst showing this in consistent behaviour with an open mind and the willingness to change.

When one compares this operationalisation of authentic leadership with the Barbuto and Wheeler (2006) and the Van

TABLE 1: The dominant themes of servant leadership.

\begin{tabular}{ll}
\hline Researchers & Themes \\
\hline Graham (1991) & Inspirational, moral \\
\hline Buchen (1998) & Self-identity, capacity for reciprocity, relationship builders, preoccupation with the future \\
\hline Spears (1998) & Listening, empathy, healing, awareness, persuasion, conceptualisation, foresight, stewardship, commitment, community building \\
\hline Farling, Stone \& Winston (1999) & Vision, influence, credibility, trust, service \\
\hline Laub (1999) & Valuing people, developing people, building community, displaying authenticity, providing leadership, shares \\
\hline Russell (2001) & Appreciation of others, empowerment, vision, credibility, trust, service, modelling, pioneering \\
\hline Patterson (2003) & Agapáo love, humility, altruism, vision, trust, empowerment, service \\
\hline Dennis \& Bocarnea (2005) & Empowerment, trust, humility, Agapáo love, vision \\
\hline Liden, Wayne, Zhao \& Henderson (2008) & $\begin{array}{l}\text { Empowering, helping, subordinates grow and succeed, putting subordinates first, emotional healing, conceptual skills, creating value } \\
\text { for community, behaving ethically }\end{array}$ \\
\hline Sendjaya, Sarros \& Santora (2008) & $\begin{array}{l}\text { Transforming influence, voluntary subordination, authentic self, transcendental spirituality, covenantal relationship, responsible } \\
\text { morality }\end{array}$ \\
\hline Van Dierendonck \& Nuijten (2011 & Empowerment, humility, standing back, authenticity, forgiveness, courage, accountability, stewardship \\
\hline
\end{tabular}

Source: Adapted from Sendjaya, S. (2003). Development and validation of Servant Leadership Behaviour Scale. Proceedings of the Servant Leadership Research Roundtable. Retrieved March 4 2013, from http://www.regent.edu/acad/cls/2003ServantLeadershipRoundtable/ Sendjaya.pdf; Van Dierendonck, D., \& Nuijten, I. (2011). The servant-leadership survey (SLS): development and validation of a multidimensional measure. Journal of Business and Psychology, 26(3), 249-267. http://dx.doi.org/10.1007/s10869-010-9194-1 
Dierendonck (2011) conceptualisation of servant leadership, it reveals an overlap of two characteristics: authenticity and humility. With its explicit theoretical roots in authenticity theory, authenticity itself is obviously more an issue of authentic leadership. With regard to humility, one also only finds the willingness to learn in authentic leadership. The willingness to stand back and give space to others is missing (Van Dierendonck, 2011). Moreover, none of the other servant leadership characteristics are explicitly positioned or measured as belonging to the core of authentic leadership. Therefore, it is also possible that leaders work authentically from agency theory to increase shareholder value, believing that it is the moral obligation of managers. This puts limits on authentic leadership as a core theory for positive leadership. However, working from a stewardship perspective and considering all stakeholders is an explicit element of servant leadership theory (Barbuto \& Wheeler, 2006; Van Dierendonck, 2011).

\section{Servant leadership and ethical leadership}

Ethical leadership is similar to servant leadership in terms of caring for people, integrity, trustworthiness and serving the good of the whole. In ethical leadership, the emphasis is more on directive and normative behaviour, whereas servant leadership has a stronger focus on the developmental aspect of the followers. Ethical leadership, as Brown, Treviño and Harrison (2005) have defined and operationalised it, is a leadership style that emphasises the importance of the direct involvement of employees, building trust and being ethical in one's behaviour. The Brown et al. (2005) conceptualisation of ethical leadership focuses on making fair decisions, displaying ethical behaviour, listening and having the best interest of employees in mind. All of these apply to servant leadership as well. Taking the five key characteristics that Barbuto and Wheeler (2006) identified as the main point of comparison, the strongest overlap occurs with empowering and developing people, humility and the stewardship nature of servant leadership.

As the previous section showed, there is a considerable overlap between the value-based theories of leadership. Servant leadership theory reveals similarities with, and differences from, other leadership theories. Servant leadership is a unique leadership paradigm that includes a strong emphasis on the motivation to become leaders with needs to serve and to promote the personal growth of followers without necessarily having a link to organisational outcomes.

\section{Research design Research approach}

The authors achieved the objectives they set out for this study by using structural equation modelling (SEM). They used a quantitative survey design to achieve their research objectives.

\section{Research method Sample}

The authors conducted the study using primary and secondary school teachers from selected schools in the Western Cape Province of South Africa. They used a nonprobability sampling strategy for the study. The sample consisted of 288 teachers from 38 schools in the Western Cape Province of South Africa. It comprised 205 female (71.2\%) and 83 male (28.8\%) employees. Most (30.9\%) fell into the 41 to 50 age group. The ethnic distribution in the sample was Black people (17.4\%), people of Mixed Race (39.6\%) and White people $(43.1 \%)$. The home language of the majority was Afrikaans (74.9\%). A minority had isiXhosa (12.9\%) and English (10.4\%) as their home languages. Most respondents had a degree or diploma $(92.7 \%)$ as their highest level of qualification.

\section{Measuring instrument}

The authors measured servant leadership using the SLQ (Barbuto \& Wheeler, 2006). Barbuto and Wheeler (2006) identified five dimensions that 23 items measured using exploratory factor analysis. The items included: 'This person goes above and beyond the call of duty to meet my needs' (altruistic calling); 'This person is talented at helping me to heal emotionally' (emotional healing); 'This person is good at anticipating the consequences of decisions' (wisdom); 'This person is very persuasive' (persuasive mapping); and 'This person believes that the organisation needs to play a moral role in society' (organisational stewardship).

Reliabilities for the self and rater versions of the scale ranged from 0.68 to 0.87 and from 0.82 to 0.92 respectively.

\section{Research procedure and ethical considerations}

The authors delivered the questionnaires personally to the various schools in the Western Cape Province, South Africa. The participants received the Servant Leadership Questionnaire. It included a covering letter and a biographical section. The covering letter introduced the reason for the study and gave instructions for completing the questionnaires, as well as information about the participants' ethical rights.

In terms of ethics, the authors received permission for the research from the institution's research ethics committee and the Department of Education. The authors sought informed consent from the participants before they completed the questionnaires. The authors maintained the confidentiality of the information or data they obtained.

\section{Statistical analysis}

The authors analysed the data through confirmatory factor analyses (CFA) via SEM.

Structural equation modelling: SEM helps to explain the patterns of covariance researchers find amongst observed variables in terms of the relationships that the measurement and structural models hypothesise (Diamantopoulos \& Si- 
guaw, 2000). The measurement model describes how corresponding manifest indicators operationalise each latent variable, whilst the structural model describes the relationships between the latent variables themselves (Diamantopoulos \& Siguaw, 2000).

Confirmatory factor analysis: The authors used LISREL 8.80 (Jöreskog \& Sörbom, 2006) to perform first- and second-order confirmatory factor analysis on the SLQ to determine the fit of the model. They treated the measurement model as an exogenous model for the confirmatory factor analysis, simply because of its programming advantages. They first read the data into PRELIS (Jöreskog \& Sörbom, 1996) to compute a covariance matrix and an asymptotic covariance matrix to serve as input for the LISREL analysis. Corresponding manifest indicators used robust maximum likelihood (RML) estimation to estimate the parameters set free in the model because of the lack of multivariate normality in the data (Jöreskog \& Sörbom, 1996).

\section{Evaluating the first- and second-order Servant Leadership} Questionnaire models: The authors based their evaluation of fit of the first- and second-order models on:

- The Satorra-Bentler Scaled chi-square.

- The root mean square error of approximation (RMSEA).

- The Root Mean Squared Residual (RMR).

- The Goodness-of-fit index (GFI).

- The Adjusted Goodness-of-fit index.

- The Normed Fit Index (NFI).

- The Non-normed Fit Index (NNFI).

- The Comparative Fit Index (CFI)

- The Incremental Fit Index (IFI).

- The Relative Fit Index (RFI).

The chi-square statistic is the traditional measure of overall model fit in covariance structure models. It provides a test of perfect fit in which the null hypothesis is that the model fits the population data perfectly. A statistically significant chisquare leads to the rejection of the null hypothesis, implying imperfect fit and possible rejection of the model. Therefore, the null hypothesis tested by the chi-square test was $\mathrm{H}_{0}: \Sigma=\Sigma(\theta)$ (Diamantopoulos \& Siguaw, 2000).

The RMSEA shows how well a model with unknown but optimally chosen parameter values fits the population covariance matrix if it is available. The RMSEA is a measure of closeness of fit. Researchers generally regard it as one of the most informative fit indices. When assessing the RMSEA, values less than 0.05 indicate good fit, those between 0.05 and under 0.08 show reasonable fit, values between 0.08 and 0.10 indicate mediocre fit and those above 0.10 indicate poor fit (Diamantopoulos \& Siguaw, 2000).

Another fit index that LISREL provides is the RMR, which is a summary measure of fitted residuals and presents the average value of the difference between the sample covariance (variance) and a fitted (model-implied) covariance (variance). The main drawback inherent in interpreting the fitted residuals (and therefore the RMR statistic) is that their size varies with the unit of measurement and the RMR varies from variable to variable. One resolves this problem by concentrating on the standardised residuals, which are the fitted residuals divided by the estimated standard errors. A summary measure of standardised residuals is the standardised RMR. Values below 0.05 show acceptable fit (Diamantopoulos \& Siguaw, 2000).

Researchers generally regard the next three measures of fit as absolute fit indices in that they directly assess how well the covariances predicted from the parameter estimates reproduce the sample covariances. The computations of the absolute fit indices do not depend on a relative comparison with a 'baseline' model. On the other hand, relative fit indices measure the proportionate improvement in fit by comparing the target model with a more restricted, nested baseline model (Diamantopoulos \& Siguaw, 2000). The GFI is an indicator of the relevant amount of variance and covariance the model accounts for and, hence, shows how closely the model comes to reproduce the observed covariance matrix perfectly. The values of the GFI should range between 0 and 1 . Researchers usually interpret values greater than 0.90 as reflecting acceptable fit. Generally, researchers recommend the GFI as the most reliable measure of absolute fit (Diamantopoulos \& Siguaw, 2000)

The next set of fit indices is the relative fit indices, which show how much better the model fits compared to a baseline model, usually the independence model. The NFI and the NNFI should range between 0 and 1 , with values closer to 1 showing good fit (Diamantopoulos \& Siguaw, 2000).

\section{Results Missing values}

The authors addressed the missing values problem by using the multiple imputation method (Jöreskog \& Sörbom, 2006). Through this technique, one substitutes the missing values with values one derives from averages via simulation (Jöreskog \& Sörbom, 2006; Rubin, 1987). Using this technique resulted in an effective sample size of 288 cases.

\section{Evaluating the measurement models}

The authors investigated the content and structure of the constructs by means of item analysis, as well as CFA, through LISREL 8.80 (Du Toit \& Du Toit, 2008; Jöreskog \& Sörbom, 2006) to evaluate the construct validity of the measurement models. The current study intended to determine whether one could confirm the constitutive meaning and factor structure, which Barbuto and Wheeler (2006) originally developed in the United States of America (USA), on a South African sample.

\section{Multivariate normality}

The default method of estimation when fitting measurement models to continuous data (maximum likelihood) assumes multivariate normality. The authors consequently evaluated the univariate and multivariate normality of the individual item indicator variables via PRELIS (Jöreskog \& Sörbom, 
1996). They had to reject the null hypothesis of univariate normality in the case of all the individual item indicator variables $(p<0.01)$.

The authors explored two possible solutions for the lack of normality in the data. The first was to normalise the individual item indicator variables. Although the PRELIS normalisation improved the symmetry and kurtosis of the indicator variable distributions, the authors still had to reject the null hypothesis of multivariate normality. The dilemma is that normalising occurs for each variable separately (Mels, 2003).

Because the normalisation option failed to achieve multivariate normality, the authors considered using an alternative method of estimation more appropriate to data that does not follow a multivariate normal distribution. Mels (2003) recommends the use of robust maximum likelihood estimation if the assumption of a multivariate normal distribution does not hold. However, because the normalisation reduced the discrepancy between the observed distribution and the multivariate normal distribution, the authors used the normalised dataset in the subsequent analysis.

\section{Item analysis}

The authors conducted item analysis using the SPSS Reliability procedure (SPSS Inc, 2011) on the items of the SLQ. The internal consistency coefficients of all the subscales of the SLQ were highly satisfactory $(\alpha>0.70)$ (Nunnally, 1978) (see Table 2). Although the Cronbach's alpha value for the persuasive mapping subscale was good $(\alpha=0.87)$, deleting item 1 could increase the Cronbach's alpha value for the subscale to $\alpha=0.89$. Nevertheless, the authors did not delete the item in order to maintain the original factor structure of the SLQ.

\section{Goodness-of-fit of the measurement models (first-order} and second-order confirmatory factor analyses)

In terms of the Goodness-of-Fit indices Table 3 reports, the $\chi^{2} / d f$ ratio for the measurement and structural models fell in the 2 to 5 range that indicates acceptable fit (Kelloway, 1998). According to this standard or interpretation, the model fits the data well. However, as Kelloway (1998) recommends, it is important not to rely solely on the $\chi^{2} / d f$ ratio, but rather to take into account a range of indices.

TABLE 2: Servant Leadership Questionnaire reliability coefficients.

\begin{tabular}{lll}
\hline Scale & Number of items & Cronbach's Alpha $(\boldsymbol{\alpha})$ \\
\hline Altruistic calling & 4 & 0.92 \\
Emotional healing & 4 & 0.93 \\
Wisdom & 5 & 0.93 \\
Persuasive mapping & 5 & 0.87 \\
Organisational stewardship & 5 & 0.92 \\
\hline Total SLQ & $\mathbf{2 3}$ & $\mathbf{0 . 9 7}$
\end{tabular}

SLQ, Servant Leadership Questionnaire.
The RMSEA suggested that the measurement and structural models showed reasonable fit with the data $(0.064$ 0.071 ), because values of $<0.05$ represent good fit whilst those between 0.05 and 0.08 indicate reasonable model fit (Diamantopoulos \& Siguaw, 2000). The standardised RMR value of 0.049 for the measurement model indicates good model fit $(<0.05)$, whilst the SRMR value for the structural model just missed the 0.05 level. The GFI values for the measurement and structural models fell marginally below the 0.90 level that indicates good fit.

The results of the incremental fit measures indicate that, when compared to a baseline model, the measurement and structural models achieved NFI, NNFI, CFI, IFI and RFI indices of > 0.90, which represents good fit (Hair et al., 2010; Kelloway, 1998). Therefore, these relative indices seem to portray a positive picture of model fit.

Table 4 gives the standardised factor loadings. The values shown in the completely standardised solution loading matrix represent the slopes of the regression of the standardised items on the standardised latent servant leadership dimension that the item was designed to represent. Therefore, the completely standardised loadings indicate the average change expressed in standard deviations in the item associated with one standard deviation change in the latent variable. The factor loadings of the items are generally significant $(>0.50)$.

Table 5 gives the correlations between the five latent SLQ dimensions. These correlations reflect the correlations between the five SLQ subscales, corrected for the attenuating effect of random and systematic measurement error. The correlations fall within reasonable limits, as high values (above 0.90) may indicate multi-collinearity (Tabachnick \& Fidell, 2001).

\section{Examination of the first-order measurement model residuals}

Large positive residuals indicate that the model underestimates the covariance between some of the variables and a negative residual shows that the model overestimates the covariance between variables (Jöreskog \& Sörbom, 1996). The distribution of the residuals in the stem-and-leaf plot (Figure 1) seems slightly positively skewed, implying that the model might be underestimating the residuals.

\section{Parameter estimates}

One uses the unstandardised Gamma matrix to assess the significance of the estimated path coefficients $\gamma_{\mathrm{ij}}$ that express the strength of the influence of $\xi_{\mathrm{j}}$ (exogenous latent variables) on $\eta_{\mathrm{i}}$ (endogenous latent variables). The parameters are significant $(p<0.05)$ if the $t$-values are $\geq|1.96|$ (Diamantopoulos \& Siguaw, 2000).

TABLE 3: Goodness-of-fit indices obtained for the Servant Leadership Questionnaire measurement and structural models.

\begin{tabular}{lllllllll}
\hline Model & S-B $\chi^{2} / d f$ & RMSEA & SRMR & GFI & NFI & NNFI & CFI & IFI \\
\hline First-order CFA & 2.17 & 0.06 & 0.049 & 0.83 & 0.98 & 0.99 & 0.99 & 0.99 \\
Second-order CFA & 2.43 & 0.07 & 0.06 & 0.81 & 0.98 & 0.99 & 0.99 & 0.99 \\
\hline
\end{tabular}

S-B $\chi^{2}$, Sattora-Bentler Scaled Chi-square; $d f$, degrees of freedom; RMSEA, root mean square error of approximation; SRMR, standardised root mean residual; GFI, goodness-of-fit; $\mathrm{NFI}$, Normed fit index; NNFI, non-normed fit index; CFI, Comparative fit index; IFI, incremental fit index; RFI, relative fit index. 
TABLE 4: Completely standardised solution LAMBDA-X.

\begin{tabular}{|c|c|c|c|c|c|}
\hline Item & 1 & 2 & 3 & 4 & 5 \\
\hline 2 & 0.80 & - & - & - & - \\
\hline 3 & 0.82 & - & - & - & - \\
\hline 16 & 0.92 & - & - & - & - \\
\hline 21 & 0.88 & - & - & - & - \\
\hline 1 & - & 0.55 & - & - & - \\
\hline 6 & - & 0.74 & - & - & - \\
\hline 10 & - & 0.82 & - & - & - \\
\hline 14 & - & 0.85 & - & - & - \\
\hline 18 & - & 0.85 & - & - & - \\
\hline 5 & - & - & 0.83 & - & - \\
\hline 7 & - & - & 0.80 & - & - \\
\hline 9 & - & - & 0.91 & - & - \\
\hline 13 & - & - & 0.90 & - & - \\
\hline 22 & - & - & 0.81 & - & - \\
\hline 4 & - & - & - & 0.78 & - \\
\hline 8 & - & - & - & 0.90 & - \\
\hline 12 & - & - & - & 0.91 & - \\
\hline 17 & - & - & - & 0.90 & - \\
\hline 11 & - & - & - & - & 0.79 \\
\hline 15 & - & - & - & - & 0.89 \\
\hline 19 & - & - & - & - & 0.86 \\
\hline 20 & - & - & - & - & 0.82 \\
\hline 23 & - & - & - & - & 0.83 \\
\hline
\end{tabular}

Source: adapted from Barbuto, J.E., \& Wheeler, D.W. (2006). Scale development and construct clarification of servant leadership. Group and Organisational Management, 31(3), 300-326. http://dx.doi.org/10.1177/1059601106287091

1, altruistic calling; 2 , persuasive mapping; 3 , wisdom; 4 , emotional healing; 5 , organisational stewardship.

TABLE 5: Phi matrix of the latent servant leadership questionnaire dimension inter-correlations.

\begin{tabular}{llllll}
\hline Dimension & $\mathbf{1}$ & $\mathbf{2}$ & $\mathbf{3}$ & $\mathbf{4}$ & $\mathbf{5}$ \\
\hline Altruistic calling & 1.000 & - & - & - & - \\
Persuasive Mapping & 0.79 & 1.000 & - & - & - \\
Wisdom & 0.81 & 0.85 & 1.000 & - & - \\
Emotional healing & 0.88 & 0.74 & 0.78 & 1.000 & - \\
Organisational stewardship & 0.66 & 0.80 & 0.81 & 0.60 & 1.000 \\
\hline
\end{tabular}

1 , altruistic calling; 2 , persuasive mapping; 3 , wisdom; 4 , emotional healing; 5 , organisational stewardship.

TABLE 6: Unstandardised gamma matrix.

\begin{tabular}{llll}
\hline Dimension & $\gamma$ & SE & $t$ \\
\hline Altruistic calling & 0.89 & 0.06 & $16.10^{*}$ \\
Persuasive mapping & 0.90 & 0.10 & $9.40^{*}$ \\
Wisdom & 0.93 & 0.05 & $17.39^{*}$ \\
Emotional healing & 0.85 & 0.06 & $15.32^{*}$ \\
Organisational stewardship & 0.81 & 0.06 & $13.43^{*}$ \\
\hline
\end{tabular}

$\gamma$, completely standardised path coefficients; SE, standard error estimates; $t, t$-values. $t$-values $\geq 1.96$ indicate significant parameter estimates.

$*, p<0.05$

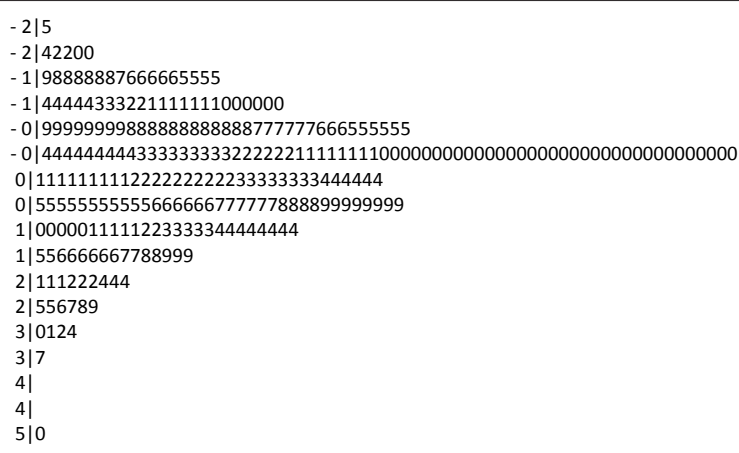

FIGURE 1: The stem leaf plot.
The authors also investigated the strength of the influence of the servant leadership higher-order factor on the five dimensions. The $t$-values show that the five dimensions are significant indicators of the servant leadership higher-order factor because the $t$-values are greater than 1.96.

\section{Power assessment}

The authors used a Rweb (1.03) translation of the SAS syntax, which Preacher and Coffman (2006) provided, to derive the power estimates for the tests of exact and close fit. In the current study, a significance level $(\alpha)$ of 0.05 , a sample size of 288 and the degree of freedom $(v)$ in the model calculated using the formula:

$1 / 2[(p+q)(p+q+1)-t]=225$

The abovementioned equation was the input for the power calculations. Here $p=$ the number of indicator variables for the $y$-variables (the five servant leadership latent dimensions), $q=$ the number of indicator variables for the exogenous variable (the second-order servant leadership variable) and $t=$ the number of parameters to be estimated.

Table 7 shows that the authors obtained a power value of 0.9999881 for the test of exact fit. This power value is reasonably large. In this case, the authors rejected the null hypothesis of exact fit. They calculated the power of the test of close fit as 0.9999987, which was high. It implied that, in the conditions that characterised this specific study, one would reject approximately $99.99987 \%$ of incorrect models. This boosts confidence in the model.

\section{Discussion}

The objective of this study was to contribute to the international research on the psychometric properties of the Servant Leadership Questionnaire, which Barbuto and Wheeler (2006) developed, by testing the construct validity of the instrument on a South African sample.

\section{Summary of the research results}

The reliability analyses confirmed that one can use the instrument reliably in the South African context. All the subscales had good reliability coefficients $(\alpha>0.80)$ (Nunnally, 1978).

The first- and second-order CFA confirmed the proposed relationships between the observed variables that comprise the five latent variables. The results show that the SLQ has sufficient construct validity. All the subscales included a sufficient number of items to provide a credible estimate of the latent servant leadership dimension. The second-order CFA confirmed that the five servant leadership dimensions contributed significantly to an overall servant leadership construct. The results of both the first- and second-order CFA show that the data has reasonable fit with the model.

The authors also assessed the individual factor loadings to determine the construct validity further. Standardised 
TABLE 7: Power assessment for the structural model for the tests of exact and close fit.

\begin{tabular}{llllll}
\hline ALPHA & RMSEA(0) & RMSEA (A) & $\boldsymbol{N}$ & POWER & $d f$ \\
\hline 0.05 & 0.00 & 0.05 & 288 & 0.9999881 & 225 \\
0.05 & 0.05 & 0.08 & 288 & 0.9999987 & 225 \\
\hline
\end{tabular}

RMSEA, root mean square error of approximation; $d f$, degrees of freedom

loading estimates should be 0.50 or higher. Ideally, they should be 0.70 or higher (Hair et al., 2010). According to this criterion, only one item (My team leader encourages me to dream 'big dreams' about the organisation) in the persuasive mapping subscale had a value of 0.55 .

Based on the outcomes of the current study on a South African sample of primary and secondary school teachers, one can conclude that the Servant Leadership Questionnaire has reasonable construct validity. This outcome confirms Sun and Wang's (2009) conclusion that the construct validity of the five dimensions of the SLQ could still hold in different cultural contexts. However, the findings are not consistent with the findings of the Dannhauser and Boshoff (2007) study in which they argued that the instrument could be onedimensional.

\section{Limitations of the study and suggestions for future research}

Future studies should determine the criterion-related validity and analyse the construct validity of the SLQ in the South African education and corporate sectors further. In addition, they should test the measurement equivalence of the SLQ in different South African gender and cultural groups.

Future studies should determine the convergent and divergent validity of servant leadership by developing a nomological network of servant leadership by linking the construct and its sub-dimensions with other related leadership styles like transformational leadership, ethical leadership and authentic leadership. Furthermore, they should replicate this study using a sample comprising employees in the public and private sectors to see whether they yield similar results.

\section{Conclusion}

The psychometric evaluation of the SLQ in the present study shows reasonable construct validity. The practical contribution of the study is that it increased the body of knowledge about the psychometric properties of the SLQ on a sample comprising teachers from the Western Cape Province of South Africa.

The study helps to advance the use of valid and reliable instruments as the Employment Equity Act (No. 55 of 1998) and the Amended Employment Equity Act of South Africa (Republic of South Africa, 1998) requires. These acts require all test developers and users to consider the psychometric properties of measures before using them in South Africa.

The Servant Leadership Questionnaire (SLQ) yielded some promising evidence of reliability and construct validity and can contribute to the scientific selection and development of educational leaders in South African schools. Servant leadership incorporates a service ethic that fosters authentic participatory management, teacher development and team building.

The Department of Education should focus on increasing effectiveness in schools by promoting the empowering and people-orientated servant leadership style.

\section{Acknowledgements Competing interests}

The authors declare that they have no financial or personal relationship(s) that may have inappropriately influenced them when they wrote this article.

\section{Authors' contributions}

B.M. (Stellenbosch University) was the project leader responsible for collecting the data, analysing the statistics and writing the article. A.S.E. (Stellenbosch University) helped to collect the data and write the article.

\section{References}

Avolio, B.J., \& Gardner, W.L. (2005). Authentic leadership development: Getting to the root of positive forms of leadership. Leadership Quarterly, 16, 315-338. http:// dx.doi.org/10.1016/j.leaqua.2005.03.001

Barbuto, J.E., \& Wheeler, D.W. (2006). Scale development and construct clarification of servant leadership. Group and Organisational Management, 31(3), 300-326. http://dx.doi.org/10.1177/1059601106287091

Bass, B.M. (1985). Leadership and performance beyond expectations. New York: Free Press.

Brown, M.E., Treviño, L.K., \& Harrison, D. (2005). Ethical leadership: A social learning perspective for construct development and testing. Organizational Behaviour and Human Decision Processes, 97, 117-134. http://dx.doi.org/10.1016/j. obhdp.2005.03.002

Buchen, I.H. (1998). Servant leadership: A model for future faculty and future institutions. The Journal of Leadership Studies, 5(1), 125-134.

Burns, J.M. 1978. Leadership. New York: Harper \& Row.

Dannhauser, Z., \& Boshoff, A.B. (2007). Structural equivalence of the Barbuto and Wheeler (2006) Servant Leadership Questionnaire on North American and South African samples. International Journal of Leadership Studies, 2, 148-168.

Dennis, R.S., \& Bocarnea, M. (2005). Development of the Servant Leadership assessment instrument. The leadership \& Organisation Development Journal, 26 (8), 600-615. http://dx.doi.org/10.1108/01437730510633692

Diamantopoulos, A., \& Siguaw, J.A. (2000). Introducing LISREL. London: Sage. PMCid:PMC1298088

Du Toit, M. \& Du Toit, S. (2001). Interactive LISREL: User's guide. Lincolnwood, IL: Scientific Software International.

Du Toit, S.H.C., \& du Toit, M. (2008). Multilevel Structural Equation Modeling. In The analysis of multilevel models. DeLeeuw and Meijer (Eds.). New York: SpringerVerlag.

Farling, M.L., Stone, G.A., \& Winston, B.E. (1999). Servant leadership: Setting the stage for empirical research. Journal of Leadership Studies, 6, 49-672. http://dx.doi. org/10.1177/107179199900600104

Graham, J. (1991). Servant leadership in organisations: Inspirational and moral. Leadership Quarterly, 2 (2), 105-119. http://dx.doi.org/10.1016/10489843(91)90025-W

Han, Y., Kakabadse, N.K., \& Kakabadse, A. (2010). Servant leadership in the People's Republic of China: A case study of the public sector. Journal of Management Development, 29(3), 265-281. http://dx.doi.org/10.1108/02621711011025786

Hair, J., Anderson, R., Black, B., Babin, B., \& Black, W.C. (2010). Multivariate Data Analysis. Upper Saddle River, New Jersey: Prentice Hall. http://dx.doi. org/10.1016/j.jmva.2009.12.014

IBM Corporation. (2011). IBM SPSS Statistics for Windows, Version 20.0. Armonk, New York: IBM Corp.

Jöreskog, K.G., \& Sörbom, D. (1996). LISREL 8: User's reference guide. Chicago: Scientific Software International.

Jöreskog, K.G., \& Sörbom, D. (2006). LISREL 8.80 for Windows [Computer Software]. Lincolnwood, IL: Scientific Software International, Inc. 
Kelloway, E.K. (1998). Using LISREL for structural equation modelling: A researcher's quide. USA: SAGE.

Ladkin, D., \& Taylor, S.S. (2010). Enacting the 'true self': Towards a theory of embodied authentic leadership. Leadership Quarterly, 21, 64-74. http://dx.dol. org/10.1016/j.leaqua.2009.10.005

Laub, J. A. (1999). Assessing the servant organisation: Development of the Organisational Leadership Assessment (OLA) instrument. Dissertation abstracts international, 60(2), 308A. (UMI No. 9921922).

Laub, J. (2004). Defining Servant Leadership: A recommended typology for servant leadership studies. Proceedings of Servant Leadership Research Roundtable, 2-3 August 2004, Regent University, School of Leadership Studies, Virginia Beach.

Liden, R.C., Wayne, S.J., Zhao, H., \& Henderson, D. (2008). Servant leadership: Development of a multidimensional measure and multi-level assessment. Leadership Quarterly, 19(2), 161-177.

Macik-Frey, M., Quick, J.C., \& Cooper, C.L. (2009). Authentic leadership as a pathway to positive health. Journal of Organisational Behaviour, 30, 453-458.

Mels, G. (2003). A workshop on structural equation modelling with LISREL 8.54 for Windows. University of Port Elizabeth.

Mulaik, S.A., James, L.R., Van Alstine, J., Bennett, N., Lind, S., \& Stilwell, C.D. (1989) Evaluation of goodness-of-fit indices for structural equation models. Psychological Bulletin, 105, 430-445. http://dx.doi.org/10.1037/0033-2909.105.3.430

Nunnally, J.C. (1978). Psychometric theory. New York: McGraw-Hill.

Parolini, J., Patterson, K., \& Winston, B. (2009). Distinguishing between transformational and servant leadership. Leadership and Organization Development Journal, 30 274-291. http://dx.doi.org/10.1108/01437730910949544

Patterson, K. (2003). Servant leadership: A theoretical model. Proceedings of the Servant Leadership Roundtable, http://www.regent.edu.

Preacher, K.J., \& Coffman, D.L. (2006). Computing power and minimum sample size for RMSEA [Computer software]. Available from http://quantpsy.org/.

Republic of South Africa. (1998, October 19). Employment Equity Act. Government Gazette, No. 19370.

Rubin, D.B. (1987). Multiple Imputation for Nonresponse in Surveys. New York: John Wiley \& Sons, Inc. http://dx.doi.org/10.1002/9780470316696

Russell, R. F. (2001). The role of values in servant leadership. Leadership \& Organisation Development Journal, 22(2), 76-83. http://dx.doi.org/10.1108/01437730110382631

Schneider, S.K., \& George, W.M. (2011). Servant leadership versus transformational leadership in voluntary service organizations. Leadership and Organization Development Journal, 32(1), 60-77. http://dx.doi. org/10.1108/01437731111099283
Sendjaya, S. (2003). Development and validation of Servant Leadership Behavior Scale. Proceedings of the Servant Leadership Research Roundtable. Retrieved March 4, 2013, from http://www.regent.edu/acad/cls/2003ServantLeadershipR oundtable/ Sendjaya.pdf

Sendjaya, S., Sarros, J.C., \& Santora, J.C. (2008). Defining and measuring servant leadership behaviour in organisations. Journal of Management Studies, 45(2), 402-424. http://dx.doi.org/10.1111/j.1467-6486.2007.00761.x

Sendjaya, S., \& Cooper, B. (2011). Servant Leadership Behaviour Scale: A hierarchical model and test of construct validity. European Journal of Work and Organizational Psychology, 20(3), 416-436.

Spears, L.C. (1998). Insights into leadership: Service, stewardship, and servant leadership. New York: Wiley \& Sons. PMCid:PMC1299410

Spears, L.C. (2010). The character and servant leadership: Ten characteristics of effective, caring leaders. Journal of Virtues \& Leadership, 1(1), 25-30.

Sun, J.M., \& Wang, B. (2009). Servant leadership in China: Conceptualization and measurement. Advances in Global Leadership, 5, 321-344. http://dx.doi org/10.1108/S1535-1203(2009)0000005017

Tabachnick, B.G., \& Fidell, L.S. (2001). Using Multivariate Analysis. Boston: Allyn and Bacon. PMid:16705786

Taylor, T., Martin, B.N., Hutchinson, S., \& Jinks, M. (2007). Examination of leadership practices of principals identified as servant leaders. International leadership practices of principals identified as servant leaders. International
Journal of Leadership in Education, 10(4), 401-419. http://dx.doi. org/10.1080/13603120701408262

Van Dierendonck, D. (2011). Servant leadership: A review and synthesis. Journal of Management, 37(4), 1228-1261. http://dx.doi.org/10.1177/0149206310380462

Van Dierendonck, D., \& Nuijten, I. (2011). The servant-leadership survey (SLS): development and validation of a multidimensional measure. Journalo of Business

Walumbwa, F.O., Avolio, B.J., Gardner, W.L., Wernsing, T.S., \& Peterson, S.J. (2008). Authentic leadership: Development and validation of a theorybased measure. Journal of Management, 34, 89-126. http://dx.doi. org/10.1177/0149206307308913

Whetstone, J.T. (2002). Personalism and moral leadership: The servant leader with a transforming vision. Business Ethics: A European Review, 11(4), 385-392. http:// dx.doi.org/10.1111/1467-8608.00298

Wong, P.T.P., \& Page, D. (2003). Servant leadership: An opponent process model and the revised Servant Leadership Profile. In Proceedings of the Servant Leadership Roundtable, Retrieved from http://www.regent.edu

Yukl, G. (2013). Leadership in organisations (8th edn.). Upper Saddle River, New Jersey: Pearson. http://dx.doi.org/10.1177/1548051811429352 